engineering, since rubber science offers a vast field of academic and utilitarian investigation and the present position of our knowledge in this field is admirably set out in this work. One excellent feature of the handbook is the synopsis which precedes each section. These synopses are written in such a way that no previous knowledge of rubber technology is essential for their full appreciation. It is important to emphasise this point, since from the title of the work one might not expect to find such readable matter.

Another novel feature of the work is the index of rubber mixings arranged on the lines of that of complex organic compounds in "Beilstein". In general, the indexing leaves nothing to be desired, since a reference can be traced from the most meagre information. The possessor of this work has, in fact, the very essence of the unique library of the Rubber Research Association on his desk. Only when one realises that rubber information is scattered throughout the hundreds of journals dealing with chemistry, physics, engineering and rubber technology, can the real magnitude of the task and the satisfaction derived from its achievement be appreciated.

W. J. S. Naunton.

\title{
Folk Medicine
}

Healing Ritual: Studies in the Technique and Tradition of the Southern Slavs

By P. Kemp. (Published in conjunction with the School of Slavonic and East European Studies, University of London.) Pp. xvi $+335+24$ plates. (London: Faber and Faber, Ltd., 1935.) $21 s$. net.

T $\mathrm{N}$ eastern Europe, and more particularly in the 1 Balkans, folk medicine may be studied as a 'going concern' more thoroughly than in any other part of the Continent. It has not yet attained, or fallen to, the status of a superstition : among the southern Slavs it is still an integral element in the everyday system of thought. For this, partially, the absence of the medical practitioner, in the modern sense, in country districts to some extent is responsible. In Macedonia, for example, a few years ago in a large area around a country town not far from Salonika, the only medical attention available was that provided by a community of Roman Catholic Sisters, whose surgical appliances, simple as they were, would have seemed a little crude and antiquated even on Molière's stage.

Miss Kemp has not only made a thorough study of the technique of the healing art as practised by the Balkan peoples; but has also submitted it to a detailed analysis in order to demonstrate the physiological and pathological theories which underlie practice, as well as the sociological, magical and religious concepts which are implied. As she points out in many connexions, the concepts which are involved are of a complex nature, and any attempt at a classification of the underlying purpose or theory of causation in the art of medicine among these peoples is apt to lead to a cross-classification. Thus individual therapy, which is purely magical, is apt to shade into a group prophylaxis, in the ritual of which it is difficult to draw the line between magic and religion. As an instance may be cited the seasonal festivals and observances, some of which, it may be said without exaggeration, are kept up solely with the object of providing medicine through their ritual. The elaborate rites at an eclipse seem also to have little other purpose. No less ambiguous is the interpretation of the hospitality shown to a stranger, for among other motives may be the hope that when he leaves he will carry with him the evil and disease which might bring harm to the community.

Miss Kemp's work is a valuable contribution to the study of folk psychology, in which students will count, among other matters for gratitude as not least, a bibliography which includes Eastern European sources freely.
Resistance of Materials

By Prof. Fred B. Seely. Second edition. Pp. xii + 436. (New York: John Wiley and Sons, Inc.; London: Chapman and Hall, Ltd., 1935.) 18s. $6 d$. net.

IN this second edition of Seely's "Resistance of Materials", the book has been completely re-set, various changes based on experience and suggestions having been made, chiefly in giving further emphasis to the engineering significance of the subject. The first part consists of a complete undergraduate course for advanced students; the second part contains a brief treatment of a number of special topics in stres analysis, likely to be helpful to the young graduate engineer who wishes to study further on his own initiative. The applications are kept in sight through. out, and many instructive examples are given in the text and at the end of each chapter. 